\title{
Chapter 28 \\ The Potential of Big Data for Improving Pelagic Fisheries Sustainability
}

\author{
Karl-Johan Reite, Jose A. Fernandes, Zigor Uriondo, and Iñaki Quincoces
}

\begin{abstract}
The use of big data methods and tools are expected to have a profound effect on the pelagic fisheries sustainability and value creation. The potential impact on fuel consumption, planning and fish stock assessments is demonstrated in six different pilot cases. These cases cover the Spanish tropical tuna fisheries in Indian Ocean and the Norwegian small pelagic fisheries in the North Atlantic Ocean. The areas encompassed by these pilots have an annual capture production above 13 million tonnes.
\end{abstract}

Fisheries provide jobs and income to coastal communities and are expected to contribute to long-term European food security and economic growth. No other bioeconomy sector appears to be as regulated and monitored as fisheries, with numerous data inputs collected (i.e., catch and effort, stock sampling, ocean environment, fishing vessel activity, sales and transactions) to better understand and control the industry. Still, there is little coordinated use of big data technologies in the sector.

Fuel consumption is a challenge for most fisheries, as it represents $60-70 \%$ of the total annual costs of a vessels' activity [1-4]. Ocean-going pelagic fishing vessels employ both energy efficient gear, such as purse seines, and energy intensive gear, such as trawls. The vessels are frequently searching for fish between fishing operations, since schooling pelagic species are migratory. The vessels have been engineered to become very flexible in their production, routing, and consumption of energy onboard [5], and several methods have been proposed for adapting vessels' operations to these variations $[6,7]$. Still, the crew often operate the vessel based on habits and preferences for certain configurations of the power system.

K.-J. Reite $(\bowtie)$

SINTEF Ocean, Brattørkaia 17 C, 7010 Trondheim, Norway

e-mail: karlr@sintef.no

\section{J. A. Fernandes · I. Quincoces}

AZTI, Marine Research, Basque Research and Technology Alliance (BRTA), Herrera

Kaia—Portualdea z/g., 20110 Pasaia, Gipuzkoa, Spain

Z. Uriondo

University of the Basque Country (UPV/EHU), Alameda Urquijo s/n, 48013 Bilbao, Spain

(C) The Author(s) 2021

C. Södergård et al. (eds.), Big Data in Bioeconomy,

https://doi.org/10.1007/978-3-030-71069-9_28 


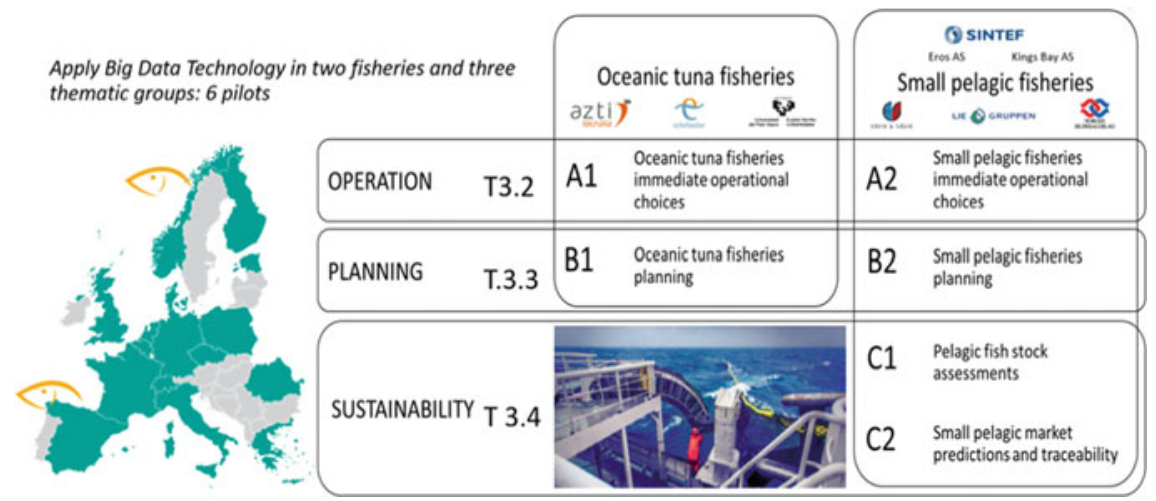

Fig. 28.1 Overview of fisheries pilots

Fishing trip planning and routing are important factors for reducing the fuel consumption within fisheries and achieving better margins. Decisions about when, where, and how to harvest are taken by expert fishers based on their own experience, information gathered from industry contacts and publicly available data. In most cases, such information is limited to meteorological forecasts, catch reports and communication with a small number of collaborating fishermen. The subjectively perceived market development is an important factor for fisheries planning, but there are no tools to assist fishermen in this respect.

Fish stock assessment is traditionally carried out based on measurements from yearly campaigns. These campaigns follow a preestablished pattern and apply both test fishing and hydroacoustic observation to sample the spatial distribution of fish in the ocean. The data from these campaigns are used in statistical models for stock estimation and resource management advice. The International Council for the Exploration of the Sea (ICES) determines quota recommendations for the national authorities, which have jurisdiction over these fish stocks. Great effort is expended in the collection of this critical data, but its spatial and temporal coverage is limited by the associated costs. In addition, consideration of market variations is important for fisheries planning to optimize the value created by fisheries. These market variations are caused by the relationship between supply and demand, which is influenced by multiple factors such as fisheries effort, fish distribution, quotas, weather conditions, competing products, and economic factors.

Part VII focuses on two separate types of pelagic fisheries: The Spanish tropical tuna fisheries in Indian Ocean and the Norwegian small pelagic fisheries in the North Atlantic Ocean. The areas encompassed by these pilots have an annual capture production above 13 million tonnes. Six separate pilot cases have been defined, addressing three separate viewpoints: (i) immediate operational choices, (ii) fishing vessel trip and fisheries planning, and (iii) fisheries sustainability and value, as shown in Fig. 28.1. 
The two "Operation" pilots aim at providing crew with information to help them perform current operations in the most energy efficient way possible, while avoiding unscheduled maintenance. To achieve this, the vessels' energy systems are monitored, and various methods are employed to supply crew direct advice.

The goal of the two "Planning" pilots is to provide information that benefits fisheries planning. The information will be provided based on extensive historical datasets of fisheries activity (e.g., VMS, GPS tracking), catch statistics (e.g., logbooks and public records), oceanographic conditions (e.g., SST, salinity, chlorophyll), meteorological conditions, and FAD data (e.g., GPS data, echosounder data, SST). The hypothesis is that large amounts of historical data combined with ocean environment near real-time information can be used to accurately forecast species distribution, by using machine learning or other techniques. This will reduce fuel consumption through targeted effort and more efficient engine operation.

The two "Sustainability" pilots investigate how long-term fish market forecasts can benefit long term fisheries planning, in particular for best timing of different fisheries to maximise economic revenue. These pilots also investigate how oceanographic simulations using fishing fleet data, as an inexpensive biomass and physical property source of measurements, can benefit pelagic fish stock assessments.

These pilots require a large amount of data to reach their goals. In addition to its volume, data collected on a large scale from a diverse set of sensors, published records and regional observation systems, also exhibits other unique characteristics as compared with data collected for a single purpose and from a single source. This data is commonly unstructured and requires more real-time analysis [8]. Many of these aspects are present in the fisheries pilots. The pilots are likely to end up producing over 5 TB of data per year and coming from many different sources. Such sources include earth observations, sensors onboard fishing vessels (i.e., acoustics, machinery, operations), simulations (i.e., meteorological, oceanographic, and marine biology) and human annotations. The update frequency, regularity, and volumes of these sources are on very different scales, affected by simulation times, vessel communications, and satellite orbits. The lack of data acquisition standardization on board vessels and data structuring poses another challenge for these pilots (Table 28.1, Fig. 28.2). 
Table 28.1 Data production by DataBio fisheries pilots

\begin{tabular}{l|l|l|l|l}
\hline Dataset type/variety & Dataset & Volume (GB) & Velocity (GB/year) & Start date \\
\hline Market data & $\begin{array}{l}\text { Catch reports, } \\
\text { economic figures }\end{array}$ & $<1 \mathrm{~GB}$ & $<0.07$ & 20120101 \\
\hline $\begin{array}{l}\text { Vessel data (including } \\
\text { buoys with sonar data) }\end{array}$ & ESAS & 67 & 18.8 & 20140901 \\
\cline { 2 - 5 } & Eros & 64 & 20.5 & 20140903 \\
\cline { 2 - 5 } & KingsBay & 78 & 19.6 & 20140826 \\
\cline { 2 - 5 } & LiegFi & 1.5 & 17.1 & 20180731 \\
\cline { 2 - 5 } & $\begin{array}{l}\text { Echebastar } \\
\text { immediate pilot data }\end{array}$ & 55 & 10.0 & 20140301 \\
\cline { 2 - 5 } & $\begin{array}{l}\text { Echebastar UE fleet } \\
\text { data }\end{array}$ & 903.8 & 602.6 & 20170101 \\
\hline
\end{tabular}

(continued)

Table 28.1 (continued)

\begin{tabular}{|c|c|c|c|c|}
\hline Dataset type/variety & Dataset & Volume (GB) & Velocity (GB/year) & Start date \\
\hline \multirow[t]{6}{*}{ EO, CMEMS, Met } & $\begin{array}{l}\text { Ocean physics } \\
\text { (current/temp) }\end{array}$ & 310 & 115.5 & 20160101 \\
\hline & $\begin{array}{l}\text { Wave data (open } \\
\text { ocean) }\end{array}$ & 283 & 165.7 & 20161209 \\
\hline & Biogeochemistry & 99.8 & 37.1 & 20160101 \\
\hline & Wind & 325 & 121.2 & 20160101 \\
\hline & Coastal waves (Met) & 1203 & 802 & 20160918 \\
\hline & $\begin{array}{l}\text { Oceanic Tuna EO + } \\
\text { research data }\end{array}$ & 938.8 & 625.9 & 20170101 \\
\hline \multirow[t]{2}{*}{ SINMOD } & $\begin{array}{l}\text { Oceanographic } \\
\text { modeling }(4 \mathrm{~km})\end{array}$ & 385 & 1752 & 20180614 \\
\hline & $\begin{array}{l}\text { NOAA atmospheric } \\
+ \text { SINMOD input }\end{array}$ & N/A & 3500 & N/A \\
\hline \multirow[t]{3}{*}{ Hydroacoustics } & \begin{tabular}{|l|} 
SIMRAD EK80 \\
series-echosounder
\end{tabular} & 3.3 & 121.2 & N/A \\
\hline & $\begin{array}{l}\text { (SIMRAD SX90 } \\
\text { Sonar }\end{array}$ & N/A & 5402 & N/A \\
\hline & $\begin{array}{l}\text { Simrad SN90 Sonar } \\
+ \text { echosounder }\end{array}$ & 317 & Per cruise & 20180612 \\
\hline WP3 Total & $\begin{array}{l}\text { All fishery pilot data } \\
\text { assets }\end{array}$ & 5004.2 & 5815.4 & \\
\hline
\end{tabular}




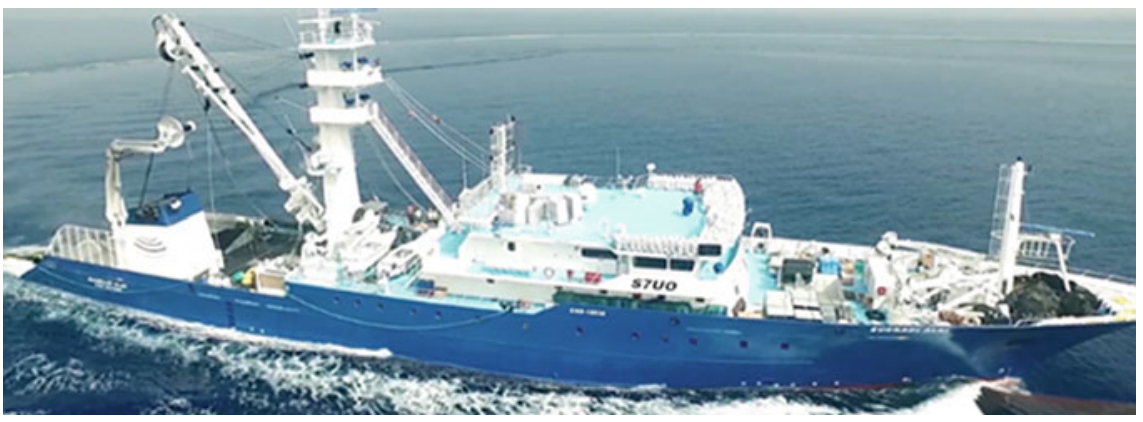

Fig. 28.2 Echebastar company tuna fishing vessel within the DataBio project

Acknowledgements The authors would like to thank the Norwegian Fishermen's Sales Organization for Pelagic Fish, for providing access to important data and for participating in discussions. The fishing vessel owners Liegruppen Fiskeri, Echebastar, Eros, Ervik \& Sævik and Kings Bay, as well as part of their crew, have participated in collecting operational data and discussions about the fishing operations and the fishing industry. Jefferson Murua (AZTI) has provided significant feedback for the improvement and quality of this chapter. The work leading to this chapter has been possible mainly through the DataBio project funded from the European Union's Horizon 2020 research and innovation programme under grant agreement No. 732064.

\section{References}

1. Suuronen, P., Chopin, F., Glass, C., Løkkeborg, S., Matsushita, Y., Queirolo, D., \& Rihan, D. (2012). Low impact and fuel efficient fishing-looking beyond the horizon. Fisheries Research, $119,135-146$.

2. Rojon, I., \& Smith, T. (2014). On the attitudes and opportunities of fuel consumption 512 monitoring and measurement within the shipping industry and the identification and 513 validation of energy efficiency and performance interventions, p. 18.

3. Parker, R. W., \& Tyedmers, P. H. (2014). Fuel consumption of global fishing fleets: Current understanding and knowledge gaps. Fish and Fisheries, 16(4), 684-696.

4. Fernandes, J. A., Santos, L., Vance, T., Fileman, T., Smith, D., Bishop, J. D., et al. (2016). Costs and benefits to European shipping of ballastwater and hull-fouling treatment: Impacts of native and non-indigenous species. Marine Policy, 64, 148-155.

5. Aursand, I. G., Digre, H., Ladstein, J., Kyllingstad, L. T., Erikson, U. G., Tveit, G. M., Backi, C. J., \& Reite, K. J. (2015). Development and assessment of novel technologies improving the fishing operation and on board processing with respect to environmental impact and fish quality (DANTEQ).

6. Reite, K.-J., Ladstein, J., \& Haugen, J. (2017). Data-driven real-time decision support and its application to hybrid propulsion systems. In Proceedings of the International Conference on Offshore Mechanics and Arctic Engineering-OMAE (Vol. 7B-2017, p. V07BT06A024-V07BT06A024). https://doi.org/10.1115/OMAE201761031

7. Skjong, S., Kyllingstad, L. T., Reite, K. J., Haugen, J., Ladstein, J., \& Aarsæther, K. G. (2019). Generic on-board decision support system framework for marine operations. In Proceedings of the international conference on offshore mechanics and arctic engineering-OMAE.https://doi. org/10.1115/OMAE2019-95146 
8. Hu, H., Wen, Y., Chua, T. S., \& Li, X. (2014). Toward scalable systems for Big Data analytics: A technology tutorial. IEEE Access, 2, 652-687.

Open Access This chapter is licensed under the terms of the Creative Commons Attribution 4.0 International License (http://creativecommons.org/licenses/by/4.0/), which permits use, sharing, adaptation, distribution and reproduction in any medium or format, as long as you give appropriate credit to the original author(s) and the source, provide a link to the Creative Commons license and indicate if changes were made.

The images or other third party material in this chapter are included in the chapter's Creative Commons license, unless indicated otherwise in a credit line to the material. If material is not included in the chapter's Creative Commons license and your intended use is not permitted by statutory regulation or exceeds the permitted use, you will need to obtain permission directly from the copyright holder.

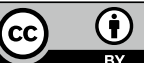

